\title{
Mobilization of Water Cycle and Its Persian Air Wheel Heat Pump to Overcome Global Heating and Its Resulting Terrible Environmental Problems
}

\author{
Malik Muhammad Nazeer \\ Islamabad, Pakistan \\ Email: Naz188nbsg@gmail.com
}

How to cite this paper: Nazeer, M.M. (2019) Mobilization of Water Cycle and Its Persian Air Wheel Heat Pump to Overcome Global Heating and Its Resulting Terrible Environmental Problems. Open Access Library Journal, 6: e5445.

https://doi.org/10.4236/oalib.1105445

Received: May 6, 2019

Accepted: June 25, 2019

Published: June 28, 2019

Copyright $\odot 2019$ by author(s) and Open Access Library Inc.

This work is licensed under the Creative Commons Attribution International License (CC BY 4.0).

http://creativecommons.org/licenses/by/4.0/

\begin{abstract}
The earth Globe and its all living inhabitants, are under extremely sever and perishing multipronged attack from the Global Heating and its team, the Greenhouse Gasses (GHG), Environmental Pollution, and Stratospheric Ozone Layer Depletion and hence Penetration of Solar Ultraviolet Radiations. The major and mother of the gang of all these dragons is Global Heating. This is mainly rising up due to continuously increasing heat input by the mankind activities like burning of the fossil fuels, explosives based warfare and jungle fires etc., on one hand and continuously decreasing its outflow on the other hand through Pollution and GHG thus evolved and through some other human contributing activities not yet exposed. To restore the climate safe status, the mankind has not only to limit heat input by strict control on all direct and indirect contributors, but also has to accelerate the heat outflow through mobilization of God Gifted Water Evaporation and Precipitationcycle (WEPC) and its catalyst, the Persian Air Wheel Heat Pump (PAWHP). Their working mechanism and capability to challenge Global Heating are elaborated in this work. The WEPC has about 75\% share in Global Heat export to the outer space, but in place of its promotion through utilizing the available opportunities, the mankind has ignorantly rolled hurdles in its natural working. All the stakeholders, especially the scientific community, are requested to urge the world leaders to mobilize WEPC and PAWHP wherever possible through United Nations Organization (UNO) and impose strict control on heat and pollution input and promote heat and pollution free means for energy generation.
\end{abstract}

\section{Subject Areas}

Environmental Sciences, Hydrology 


\section{Keywords}

Water Cycle, Global Heating, Evaporation, Precipitation, Global Heat

Export to Outer Space, Persian Air Wheel Heat Pump

\section{Introduction}

The Earth Globe and its inhabitants, both human beings and all other living creations, including plants and vegetations, both on the surface of earth and inside the depths of the Oceans are under extremely sever multipronged attacks, both direct and indirect from Global Heating, Environmental Pollution, Greenhouse Gasses (GHG) Emission, Stratospheric Ozone Layer Depletion and hence failure in complete blockage of Penetrating Solar Ultraviolet Radiations. Almost all these deadly dragons are advancing jointly in the leadership of Global Heating due to continuous increase of heat input and decrease in its outflow from the Earth Global environment. The heat inputs by the Sun radiations to the earth environment are almost constant from centuries, but its input mainly by human activities without its balancing and defusing measure is continuously raising Global Heat Contents and Temperature at critically increasing rate. Also outflow of Global Heat through its radiations from the earth to the outer Universe is continuously slowing down by GHG, pollution and soot as a result of human activities, thus continuously jeopardizing its safe mutual balance. As per survey almost $99.9 \%$ scientists agree that Earth Globe is warming and about $97 \%$ agree that it is mainly due to human activities [1]. The gravity of the situation is so high that a few decades before situation was named as Climate Change, thereafter it was generally agreed to be renamed as Global Warming and now "Global Heating" is a more accurate term than "global warming" to describe the changes taking place to the world's climate, according to a key scientist at the UK Met Office [2]. The tragedy is that this critically acute problem is not being felt and no proper remedial measure like the one suggested in [3] is being taken to defuse its brutality and gravity. The warning hues and cries for alerting the rulers, intelligentsia, media and the general public are being mocked by some irresponsible scientist; mostly of irrelevant fields, some irrelevant gapi-shapy media and non-field actors like the one says that his car is buried in snow and people say Globe is warming. Is it this? Yees, it is this, due to Global Warming and stage may come soon that you along with your car or even your house are buried and smashed under the snow and hail storm or crushed or thrown away by the hurricanes as a result of huge quantity of Global heat escape/outburst through huge water evaporations and its precipitation with extra large wind and snow storm, hurricanes and floods. And alas, a head of state of a superpower tweeted, is this the global warming? His scientific advisory community is perhaps unable to brief him properly.

The ever increasing main human activities are burning of fossil and atomic 
fuels (for power generation, industries, transport, domestic uses), huge quantities of explosive use in warefares, nuclear tests, air traffic, satellites launches and numerous large jungle fires. This raises the environmental heat contents, temperature, soot, pollution and greenhouse gasses (GHG). The last three are again adding to global Heat contents and temperature through blocking the heat outflow to the Outer Universe. These all are thus extremely detrimental to the life on the earth. From the few decades, huge increased in the Global heat contents and temperature has been observed as can be seen from Figures 1-5 respectively from references [4] [5] [6] [7] [8], thanks to USA and its Allies for promotion of large scale warfare throughout the world with huge quantity of heat, pollution and GHG input. This has slowed down the steady outflow of large quantity of global heat. It may be noted that global WEPC (Figure 6) [9] is most important, efficient and largest Global Heat Transporter to the Outer Universe, but since 1973 it is unable to compensate the global heat and temperature growth, perhaps its natural disposal routine has been blocked. As discussed below almost 75\% of Global Heat export to the outer space is through WEPC and rest $25 \%$ is by direct radiations and reflection from the land, water surface and earth atmosphere other than clouds and water vapors (Figure 7) [10]. The tragedy is that in place of increasing the

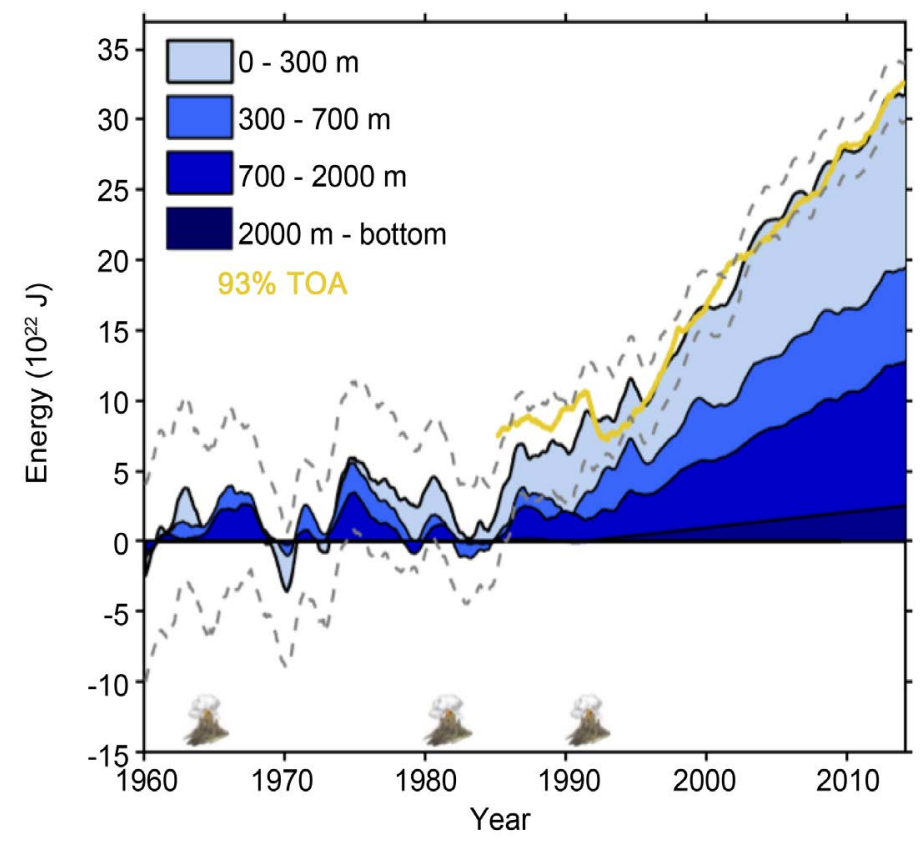

Figure 1. The graphs above show the Estimate of the ocean energy budget relative to $1958-1962$ base period, and is claimed to be more realistic. The three major volcanic eruptions are also shown and their ultimate cooling may clearly be observed. The oceanic total heat is $93 \%$ of the total Global heat contents and only $7 \%$ is the total heat energy of land + ice + atmosphere [4]. Annual rate of total Oceanic heat rise $=10 \times(31.8+19.15+12.75+2.3) /(2014-1971)=15.33 \mathrm{ZJ}$ $\left(\mathrm{Z}=10^{21}\right)$. The annual rate of total global heat rise $=10 \times(31.8+19.1+$ $12.7+2.3+4.96) /(2014-1971)=16.48 \mathrm{ZJ}$. 


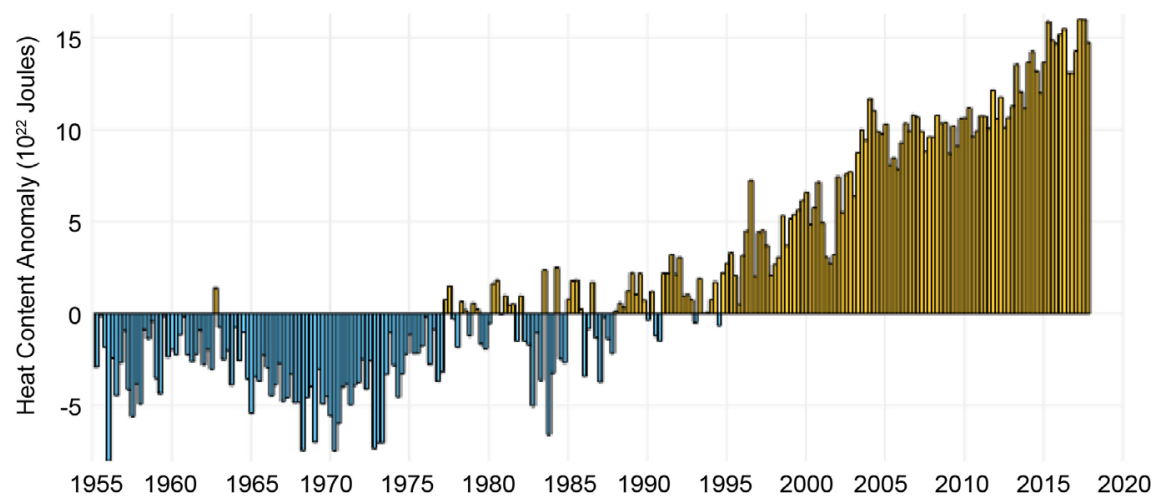

Figure 2. This graph (source data) shows differences from the long-term average global ocean heat content (1955-2006) in the top 700 meters of the ocean [5]. Rate of heat rise per year after $1972 / 73=10 \times(17+4) /(2017-1972)=210 / 45=4.7$ ZJ $\left(\right.$ Zeta Joules $=10^{21}$ $\mathrm{J})$.

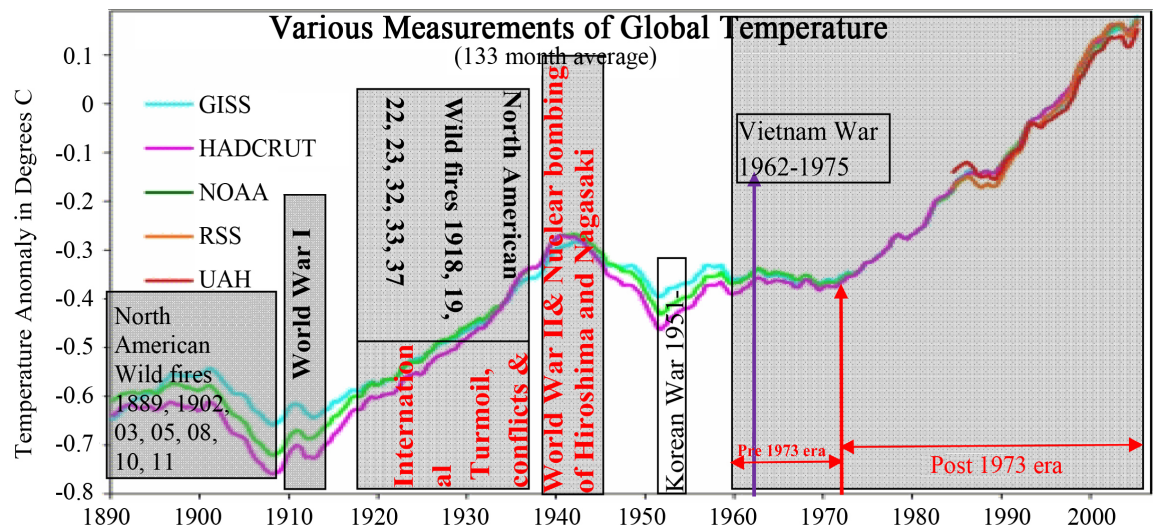

Figure 3. Global warming and Climate change [6]. Global Temperature boasting (GTB) Role of major events is quite evident. Early three events are time bound, while the $4^{\text {th }}$ one is continuous and physical matching of their behaviors (keeping lagging time in view), speaks of their dominating role in (GTB).

WEPC performance to cope with the rate of heat input boast to Earth Globe through population and industrial growth, its transfer to outer Space has been blocked by huge addition of GHG and Pollution in the environment and other foolish measures by the ignorant state actors, renowned intuitions, World leaders due to the irresponsibility of Scientific Community in general and UNO in Particular.

The hues and cries against the human input of heat and pollution in the environment has been tactfully suppressed and these has brought the earth globe to almost threshold position and now any sizeable addition of heat to it is not absorbed safely, rather triggers the disaster through huge wind and snow storms, hurricanes, tornados, cyclones, floods, heat strokes, tsunamis etc and frequent volcanic eruptions. A recent example of such worldwide disaster is that of California Jungle Fire of 2017-2018 and Hawaii volcano-2018 outburst [11], which has ruined various areas of the word again and again in its almost four round of disaster. 


\section{Observed global annual average temperature deviations in the}

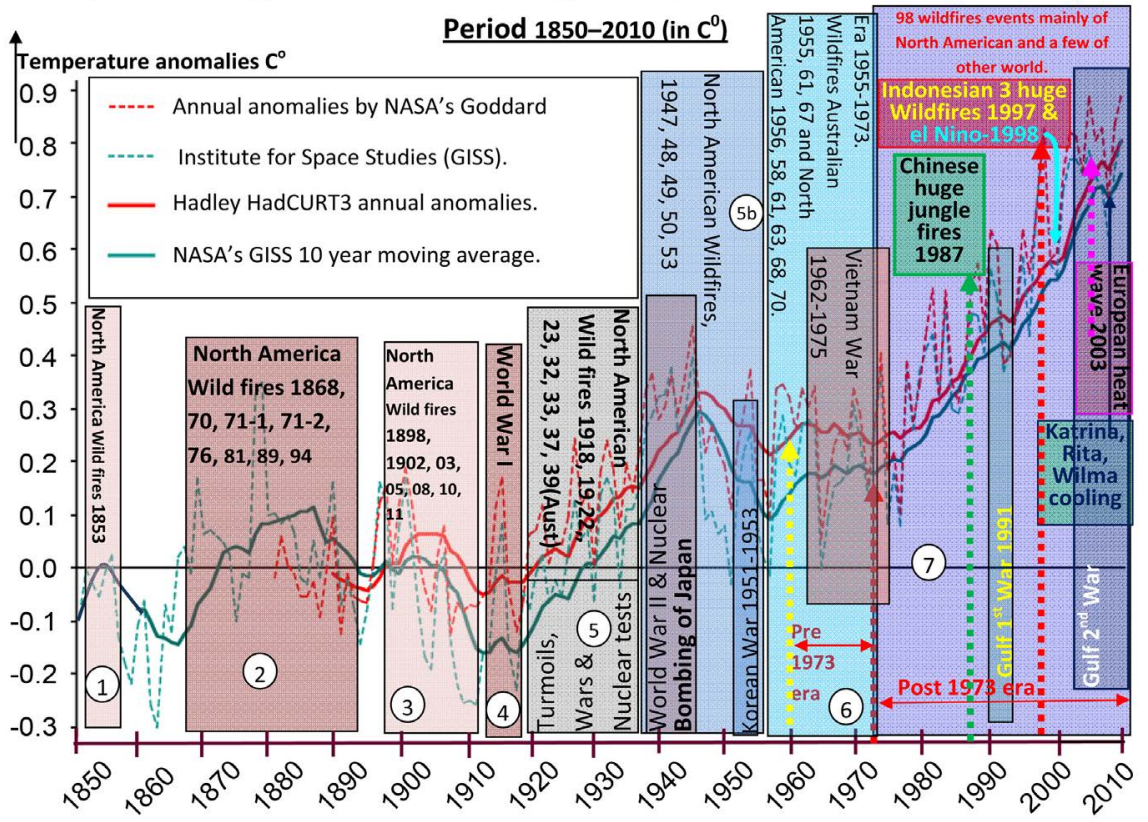

Figure 4. Rise, fall and rates in Temperature graphs [7] matches with the start, end and quantities of heat inputs by the large events marked above. Cooling after the event catered by water evaporation and precipitation cycle with heat export and cold fresh water and ice import is forced by local high temperature in eras marked $1-5 b$ for the group of events shown above. The continuous steep rise of temperature after 1960 (era 6 and 7) is attributed to some particularly extraordinary event overruling and dominating cooling routine at the end of all other events.

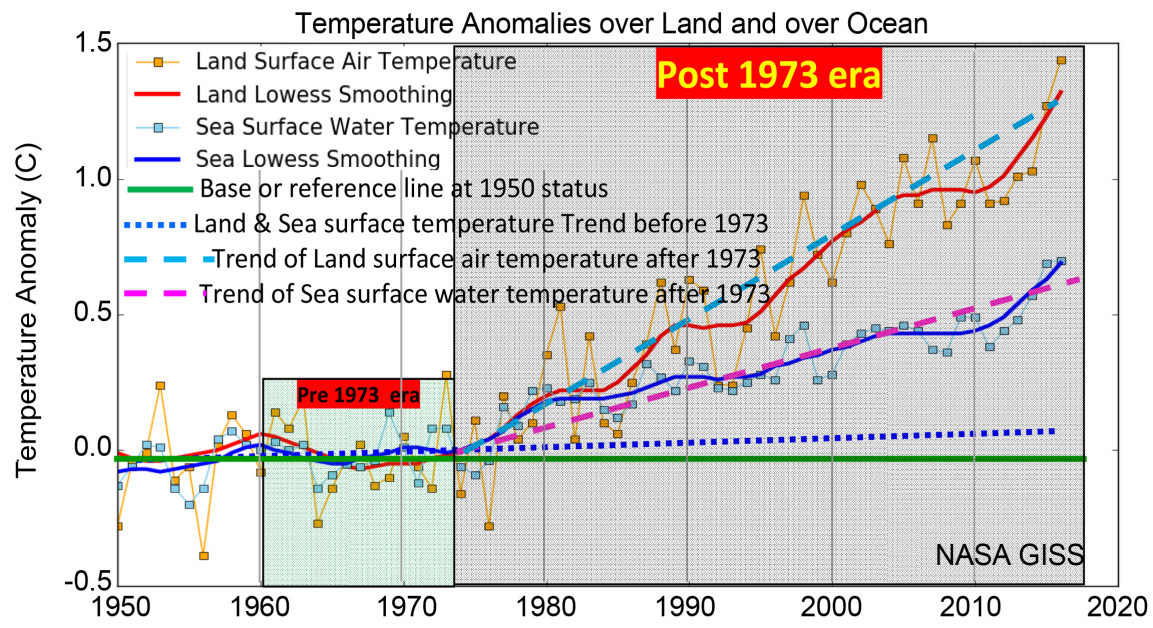

Figure 5. Sea and earth surface temperatures, their smoothing and trends before and after $1973[8]$.

\section{Water as Global Problems Reliever}

With the growth in population and rise of Global temperature, the cooling requirements are increasing and unfortunately these too are being met with through more and more heat input to the earth environments along with generation of more and more obstruction to heat outflow radiation by its side products, soot, 


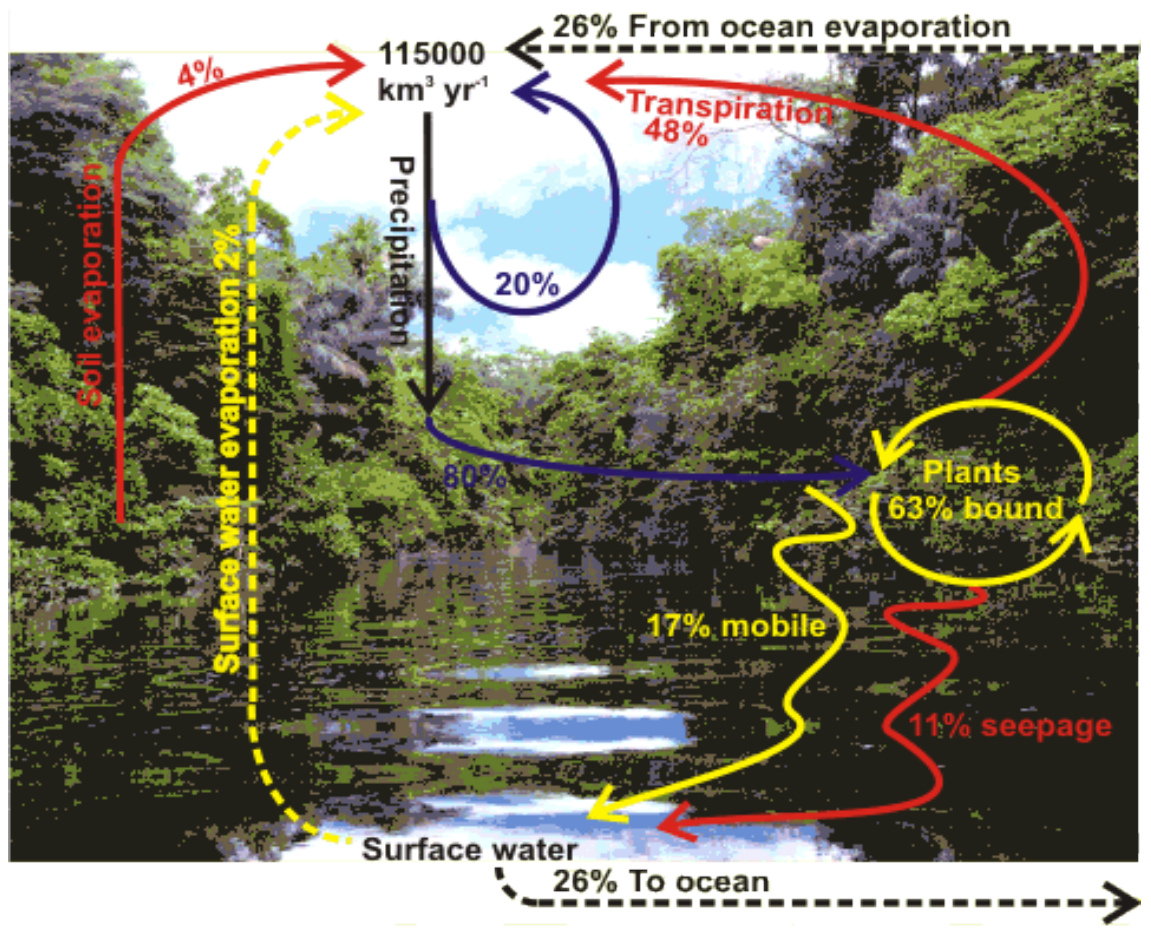

Figure 6. Global water evaporation and precipitation cycle [9].

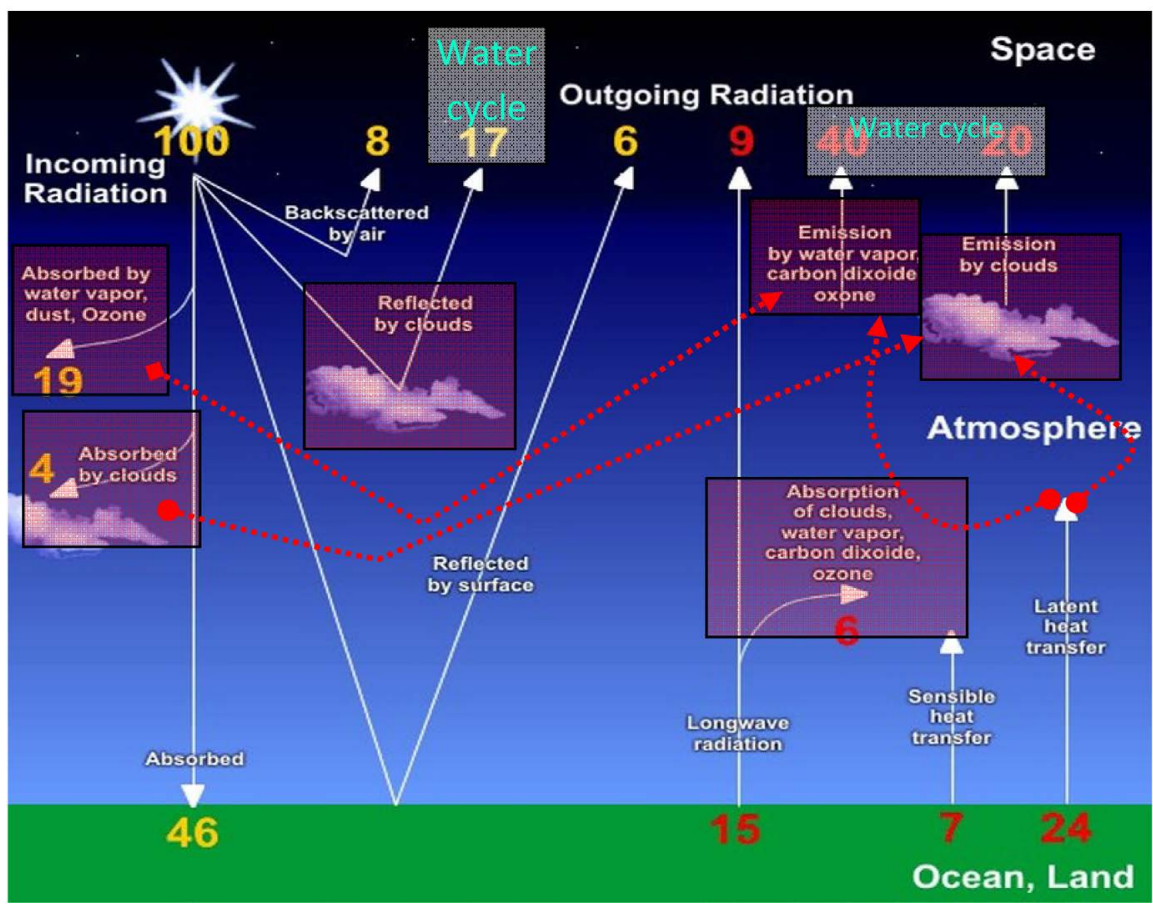

Figure 7. Global heat budget [10]. The water vapors related heat promotion to outflow $\left\{40-2\left(\mathrm{CO}_{2}\right.\right.$ and Ozone $\left.)+20+17=75\right\}$ are cloud reflections, cloud absorption, cloud emission as shown highlighted in this figure by reddish blocks for comparison with its latent heat.

pollution and GHGs and hence more and more growth of Global Heat Contents and Temperature (GHT). This in turn is feeding all the members of hurricanes 
and storms family. Thus, this closed cyclic phenomenon is self supporting and self expending using mankind's malfunctioned activities for its growth. For overcoming these problems, The Nature has provided an extremely huge compatible setup, rather a Giant Engine (Global Air Conditioner) not only to save existence of the life on this planet and neutralize unwanted side effects of the human activities, but to reverse them for human benefits and welfare. This Engine needs human role in its assembling, commissioning and mobilization through development of some important infrastructure by International Joint Venture managed and sponsored by UNO without any territorial, religious, sectarian and socio-political bindings or restraints.

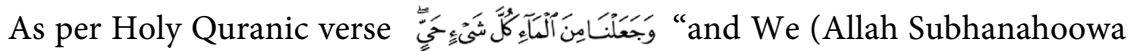
Ta-aala) have made everything living from the water", the Nature has employed the water to balance this Global heat abnormality and normalize the temperature to subdue the problem thus generated and provide clean and fresh water and atmosphere for safe existence of the life on the earth through three water based processes, two emergency or interim and one permanent and proper relievers. The Nature has provided large capacitor of heat in form of large oceans and seas on one hand and melting of polar and glacier ice and snow on the other hand for controlling the environmental abrupt temperature rise and its extremely disastrous consequences. These two are just quick, interim and emergency relievers with no opportunity for any human role or control. The $3^{\text {rd }}$, the major, exact, with multiple benefits and most suitable solution is the water evaporation and precipitation cycle (WEPC). This cycle is already in action by the Nature, but this is accompanied by extraordinary losses, damages, problems through extremely large storms, hurricanes, rains, floods etc in the scenario of highly elevated Global Heat Contents and Temperature and extraordinary huge and abrupt heat input mostly by the human beings. The mankind is thus required to review its role in heat, GHG and pollution input and also manmade obstructions in its out flow to the outer Universe. The mankind as a whole has to endure in both these directions for safe existence of life on this Globe. The mechanism and role of these three processes is pointed out here below.

\subsection{Oceanic Heating}

This is just an emergency/critical measure of diminishing the environmental temperature through absorption of heat by Oceans and seas and thus increasing their own temperature which has its own implications in the marine life culture. The huge quantity of heat is absorbed by the oceans water as shown in Figure $8(a)$. This is just to moderate and streamline the atmospheric temperature and is to serve as heat capacitor and has no human role in it at all. It will relieve the extremely sever season but will assist/promote wind and snow storms, hurricanes, Tornados, rains and floods initiated by large heat activity on the land. Their own temperature rise may promote magma based earthquakes, tsunamis and eruption of volcanoes by the reduction of heat out flow from the interior of the earth 


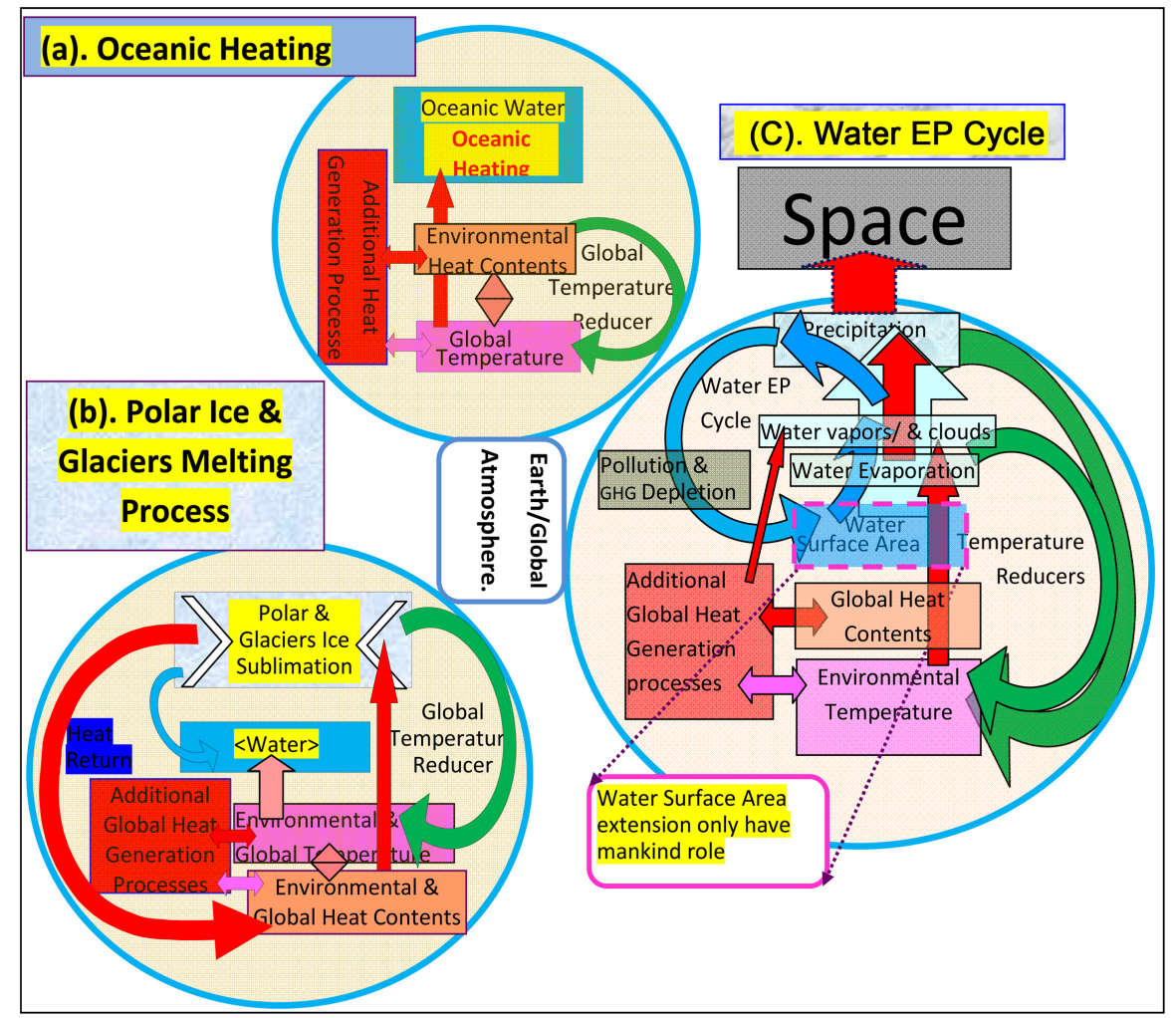

Figure 8. Comparison of water EP cycle with oceanic heating and polar \& glaciers ice melting process with respect to global heat and temperature response.

to its surface as a result of reduction in driving temperature difference. This is however, highly detrimental for the marine culture.

\subsection{Melting of Polar and Glaciers Ice}

This is also just an emergency/unwanted measure through polar and glaciers ice sublimation. This reduces the environmental temperature rise but the heat contents remain within the earth Global environments as is shown in block diagram Figure 8 (b). This is just a transport of the heat from atmosphere to water through bloodshed of polar and glaciers ice. This reduces Global ice and increases the water and raises water surface in Oceans with no space or opportunity for any human intervention or role. What will happen when whole the ice is exhausted? Then only water EP cycle will have to discharge this responsibility, which has its own limitations and will accompany with the huge disaster through hurricanes, floods and snow storms etc.

\subsection{Water Evaporation and Precipitation Cycle (WEPC)}

This is the water evaporation from the open surface of water, Oceans, seas, lakes, ponds, land surface, trees and vegetations, respiration and perspiration of all living creations on all over the world absorbing both the water and environmental heat with reduction of local heat contents and temperature. It then precipitates at high and cold altitude with rain water returning back again to the earth 
and heat thrown away to the Outer Space (Figure 8(c)). In short, this reduces both the Global Heat Contents and Temperature of the earth environments along with provision of fresh water and clean environment. It seems to be a simple process of absorbing the environmental heat as latent heat of water evaporation and then discharging it to highly cold area at high altitude, but it has number of other Global heat transporting components working along with the above stated two processes. Before evaporation water absorbs heat from both sun and mainly the earth environment to warm up close to the environmental temperature. This includes the latent heat of snow and ice sublimation. Then after absorbing latent heat during evaporation, it absorbs further heat from the global environments through all the three conduction, convection and radiation processes. It then, absorbs further heat from the sun and earth radiations along with reflection of some of the sun heat radiations back to the Outer Space and some of the earth heat radiations back to the earth, both during visible clouds and invisible vapors states. Thus it is not only the latent heat of evaporation which is transferred to upper atmosphere by evaporation and precipitation cycle Figure 6 \& Figure 7 [9] [10], but it has also the following processes transporting heat to outer space with their status compared to incoming sun radiations as $100 \%$.

1) Latent heat $24 \%$

2) Sun heat radiations

a) reflection by clouds $=17 \%$

b) absorptionby clouds $=4 \%$

c) absorptionby water $17 \%$

3) Earth long wave heat radiations

a) absorption by the clouds $6 \%$

b) absorption by water vapors(superheating) $7 \%$.

Thus even neglecting the latent heat absorbed by sublimation of snow, the WEPC emit $75 \%$ to the outer space in place of only $24 \%$, the latent heat as shown in Figure 7. This shows that the actual role of WEPC in heat pumping to the outer Universe is more than 3.125 times than that by its Latent heat of evaporation.

\subsubsection{Water Vapors a Global Heat Diffuser as Greenhouse Gas}

A few people in this field could not understand the role of water vapors in defusal of Global Heat Contents and Temperature as pointed out above and they are sticking with the notion that, it absorbs a large part of the earth radiations and also reflects a large part back to the earth being a major component of GHG blanket, thus contributing heavily to global heating.

1) Although by mass and volume, water vapors is the most dominant greenhouse gas and holds almost $95 \%$ of the total of heat held by all the greenhouse gasses, yet it certainly is not the primary culprit responsible for global heating. As the other greenhouse gases like $\mathrm{CO}_{2}$, warm the atmosphere and thus air is able to hold more water vapor. The water vapor traps more heat 
and further warms the atmosphere, but it transmits this all to the outer universe at its precipitation.

2) Water vapor returns to the Earth as water at precipitation almost within a week or so of its entering the atmosphere, whereas $\mathrm{CO}_{2}$ stays in the atmosphere between 50 - 200 years [12]. Thus in place of global heating, the water vapor as GHG is rather weekly cyclic transmitter of heat to the outer universe.

3) Moreover on precipitation the rain water and snow drag down some of the GHG, pollution and soot to the earth diminishing their GHG activities and cleaning the environment. Therefore, water vapor or WEPC is rather restoring back the environment to the safe and healthy state by reducing Global heat, temperature, pollutions, soot and GHG rise.

Thus in place of limiting control on water vapors, the best way to control global warming is to increase the water evaporation and precipitation process and reduce $\mathrm{CO}_{2}$ emissions. Human activities have increased $\mathrm{CO}_{2}$ output, and it can reduce its production for global safety. Almost $95 \%$ of heat retained/absorbed by the GHG blanket is in water vapors and it is ultimately transmitted to upper atmosphere at clouds formation and precipitation cycle of hardly a week duration.

\subsubsection{Water EP Cycle, a Major Global Heat Exporter}

As estimated above, $75 \%$ of the Global heat is exported to the Upper Cold Atmosphere by Water Evaporation and Precipitation Cycle (WEPC) Figure 7 [10] and only $25 \%$ by all other means. Thus this cycle Figure 6 [9] as a whole is the major diffuser of Global heat and major dimmer of global temperature. Apparently, evaporation takes place at the surface of water and absorbs environmental heat from the surroundings as latent heat for its evaporation and furthers more for its superheating. Then, it goes by and by to the highly cold Upper Atmosphere, partly due to being lighter in weight than air and partly by the push of the wind through the valleys and over the high mountains. Here, it hands over the heat to the upper cold atmosphere during precipitation and returns to the ground in form of rain water and snow. The temperature drop and Heat absorbed during evaporation is generally slow and is not felt much, while water heat absorption part is much felt at and immediately after precipitation, may that be in form of snow fall or even the rains.

Water vapors, actually reflects some of the sun radiations to the outer space and some of the earth radiations reflected back to the earth, while some are absorbed and transmitted to the outer Universe at precipitation and the net balance is positive in favor of the heat outflow to outer space. The $95 \%$ heat retained by water vapors as compared to the total retained by all greenhouse gasses is transported to the outer space repeatedly after every $6-8$ days. Thus more the water vapors, more will be the heat pumped out of earth atmosphere, although it will be reflecting some of the earth radiation back to the earth. The WEPC is highly favorable in the absence of preceding wildfires, volcanic outburst, explosive use in warfare and human burning of huge quantity of fossil fuels. If these 
precede, then with abrupt rise of temperature by these, it is extremely disastrous through its herd of huge hurricanes, tornados, wind and snow storms, rain, floods and preceding acute famines and fatal heat waves. The mankind has thus to control its abrupt feeders and promote its systematic, non violent and steady state growth throughout the year.

\subsubsection{Human Boasting of Water Cycle}

In the WEPC, precipitation part is closely follower of the evaporation and it neither has any opening for any human role, nor much needed except some local artificial precipitations for some local requirements. Whereas the evaporation, the leader one, has a suitable and prominent mankind role, if intelligently managed and enthusiastically implemented. This mankind activity/role, however, should not help or add much to the growth of its above stated unwanted side effects; rather divert these to benefit the mankind further more from these too. The acceleration of evaporation is the acceleration of whole WEPC and this directly depend upon 6 parameters given in the following Table 1 .

The last four of these six, do not have any access by the mankind, while the first two can have human role which may add to, accelerate and regulate the process. This is through forcing the maximum available water to steady evaporation process stretched over all 365 days of a year as far as possible. This means that seasonally available large quantity of water must be stored in dams to regulate their supply throughout the year to the irrigation and urban usage systems to enable its surface extension and enabling it to transport the environmental heat to Outer Universe throughout the year in place of its going to existing water bodies where it adds nothing to evaporation as its surface cannot be extended above the existing one. This requires development of adequate storage dams, irrigation system, agricultural fields or otherwise wherever the above stated other four factors favor the evaporation process. This activity needs intelligent management to achieve the goal without adding to and helping in emergence of its possible disaster. When seen at the broad spectrum over the entire Globe with the above in view, it seems that God has willfully created a Giant life saving system on the Globe with ideally matching all the components throughout the world for its safest role as most efficient WEPC with large opportunities of mankind role and Divinely created most ideal contributors and facilitators, both

Table 1. Water Evaporation parameters.

Parameter influencing Evaporation
1) Availability of required quantity of water


locals and Global.

The Persian Air Wheel Heat Pump (PAWHP) as described below is the one particular location and situation based functionality playing the role as repeater of almost all of these heat transport functions of WEPC.

\subsubsection{Persian Air Wheel Heat Pump (PAWHP)}

One of the extremely important boasters of WEPC cycle is its pumping of the Global Environmental Heat to the Upper Cold Atmosphere almost like the Persian Wheel pumping water from the well. This Persian Air Wheel Heat Pump (PAWHP) is actually the boaster through repetition of WEPC during its rolling movement accompanied by working of all its heat transporting components. This is Tropical and Equatorial Based Activity, but mainly of Northern Hemisphere having most of the highly heated deserts. When air is heated at the surface of earth [13], especially the barren desert, it rises up due to becoming lighter in weight or density (Figure 9). As it rises up, it start lagging westward with respect to the eastward rotating earth. As it carries on rising upward, its diameter of circular motion around and along the earth carries on increasing almost equal to its rise. Its circular linear speed around the earth being constant, its angular speed thus carries on decreasing and hence it carries on lagging with respect to an observer on the earth surface till its maximum height at the cold upper layer (Figure 9). This combined with all its followers form a semicircle of about a 10 $\mathrm{km}$ diameter. Here at the cold layer, it starts departing its heat contents and thus become heavy and starts descending. Now, opposite to its upward journey, its diameter of circular motion carries on decreasing and its angular speed carries on increasing in reverse order till it reaches the initial layer, lagging the initial location equal to circumference of its circle of $10 \mathrm{~km}$ diameter plus slipping distance if there is westward wind also as shown in Figure 9. This completes its circle and it with all its follower parts of the said layer complete the formation of westward rolling gales or the air wheel (Figure 9) [13]. These wheels carry on

\section{Air Wheel Rotation and Lagging}

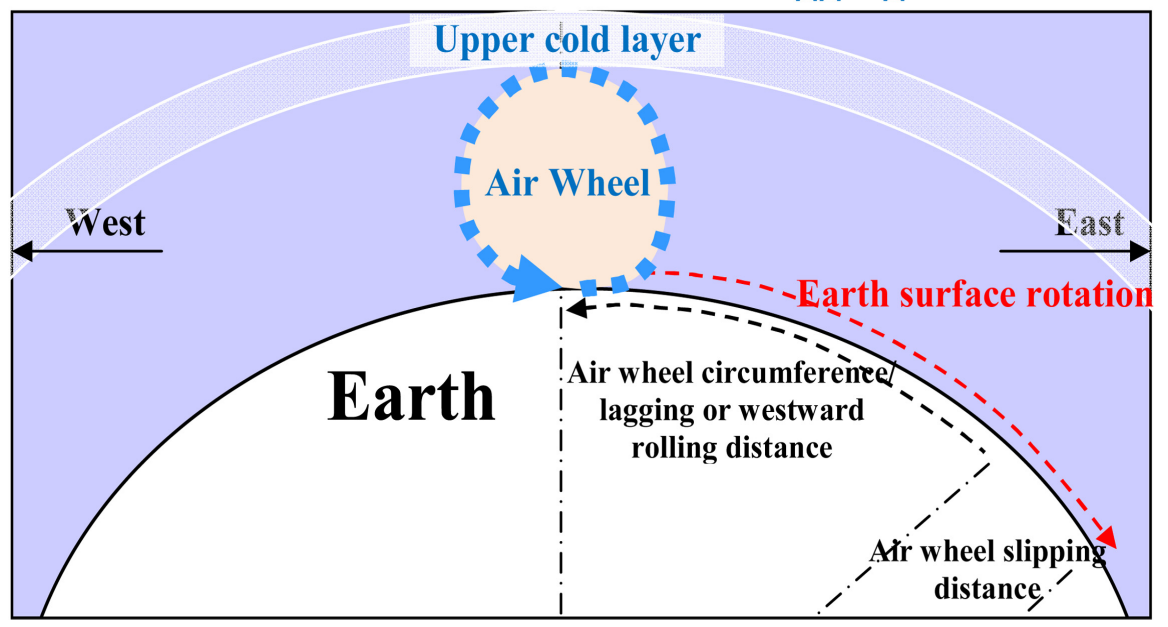

Figure 9. Earth and its rotation with air wheel generation, rotation and lagging. 
building in mass and volume while moving westward till the earth surface status is changed. When these air gales/wheels pass over the water containing surface or through the vegetation and plants, they pull in the water vapors from the surface of all these water or moisture containing bodies. When these water vapors and clouds in the air wheels roll in between the lower hot and upper cold air layers, it carries on continuously absorbing the heat from lower hot layers and discharging it in turn to the upper cold layers in every part of every turn throughout its journey by shallow WEPC (i.e. incomplete precipitation) much over and above that of dry air wheel. The hot earth surface carries on generating air wheels of up to about $10 \mathrm{~km}$ diameter (average height of troposphere). Their number is almost equal to local earth rotation speed, multiplied by 10 hours, the earth surface hottest period during sun light in the day divided by east-west elongation of the desert. Here in Pakistan it is a train of about 16 to 20 air wheels per day one after the other. The 14 hours around night is the gap between these trains.. Such area may also generate these wheels side by side, if the generating desert is much wide in north-south direction or its north and south ends are not at the same longitudes. The PAWHP phenomenon is more prominent around the Equator and in both the tropic zones especially the Northern one dominated by highly heated deserts.

\subsubsection{Heat Transport Potential of Wet and Dry Air Wheels}

Water vapors heat absorption and discharge is much larger than dry air due to their large latent heat along with clouds heat absorption, reflection and transportation actions. As stated above, water cycle role is $75 \%$ and reflection of sun radiation and earth long wave radiation directly from the earth surface is $6+9=$ $15 \%$ (Figure 7). Thus the balance for role of the dry air is at the most $10 \%$. Therefore, where the dry air wheels role is 10 , that of water vapors blended air wheels is $75+10=85$, i.e. 8.5 times that of dry air wheels. In other wards dry air wheels are only $11.76 \%$ as compared to water vapors saturated air wheels. This heat absorption and discharge of air and clouds wheels can be easily observed in the rolling and slipping clouds, when they disappear from sight as they come down to the lower hot layers absorbing heat and reappear again when they discharge part of their Latent and Super heat to the upper cold layers and this carries on throughout their total journey over and above its other activities. The heat transported by this depends on amount of water vapors in the air, Temperatures difference of the top and bottom air layers, it's rolling and slipping or translation speeds, its distance travelled especially on the earth before its complete precipitation. As these air wheel saturated with water vapors, roll between hot and cold air layers without complete precipitation, they may impart only about two third of 24 units of its latent heat, thus at the most their heat transportability may be 75 in place of 85 with respect to 24 as latent heat.

\section{Water EP Cycle and Extraordinary Global Heat Buildup}

The above referred, all the three water based processes block the huge tempera- 
ture rise to some extent, but are unable to completely balance it and hence the average Global Temperature and Global Heat Content is on the rise almost from the break of $20^{\text {th }}$ Century. All the Figures 1-5 show the heat and temperature rise with their fluctuations. In Figure 3 and Figure 4, time era of heat based Global events have been marked, which show the close coherence of timings of bulges with these events and drop in Global temperature at their end with generally imparted positive residual heat to the Global environment and net small rise in temperature. This drop in heat contents and temperature from their abrupt buildup is surely due to abrupt agitation of WEPC by the abrupt added heat and hence temperature rise in limited area and time and hence this WEPC has transported most of this heat input to the Outer Universe. The wildfire hazards are promoted by the Global heating and some may even be initiated by it and these in turn promote the global heating too, thus bilateral mutual promotion of their buildup. Such abrupt agitations of WEPC are mostly accompanied by hurricanes and storms family attacks. Thus the mankind has to lead in steady and systematic promotion of WEPC to control the Global Heating and not let it to be agitated by the abrupt heat based events.

\section{Discussion}

All these 1 - 5 figures show extraordinary hike in GHT rise around 1973 with almost no appreciable cooling contrary to the large era before 1960. It has gained critical speed particularly since 1973 and might have been promoted somewhat by wildfires and extraordinary explosive use in warfare by USA with both its allies and opponents and particularly by blocking the operation of water EP cycle and its PAWHP to be presented in a separate work. The Nature is warning the mankind through extraordinary storms, hurricanes, tornadoes, hails and snow storms, heavy rains, huge floods, tsunamis, extreme temperatures, heat waves, draughts, volcanic eruptions, earthquakes and hence the extremely huge disasters etc. to mend its ways and intelligently solve the problems created by its heat based ever increasing energy generation and other heat, pollution and GHG addition activities. On one hand, the mankind has to limit the heat input to the atmosphere by reducing the burning of the above stated fuels through developing the heat free energy generation sources like hydro, wind, solar and Oceanic tides and currents based power generation along with extremely tight control on wildfires and explosive use in warfare. On the other hand, it has to focus on acceleration and promotion of its out flow. Out of the above stated three natural processes of environment temperature control already in action, the first two are neither favorable as they do not remove heat from the earth Globe, nor are accessible for any mankind role. The WEPC is most suitable as it reduces the temperature through dissipation of undesirable accumulated Global Heat and has wide opportunity for mankind role with most suitable and beneficial side and byproducts, like control of all terrible dragons, huge agriculture, aquaculture and dairy products, the dire need of the time. 


\section{Conclusions}

From the above, it can be concluded that:

1) Systematic and steady human mobilization of Water EP Cycle is most suitable, leading to multiple most favorable outputs of tremendous Global concern over and above it being the Major Global Heat Exporter to the outer Universe.

2) Water vapor as an abundant GHG is highly suitable medication and perfectly reliever of global highly dangerous fever.

3) PAWHP is most suitable repeater of WEPC for global heat dissipation.

4) To decline and reverse the present GHT buildups indicated by Figures 1-4 stepping up with extremely Ultra hard seasons over the entire Globe, the WEPC and PAWHP need immediate mobilization.

5) To control the overall global environmental problems, comprehensive development of seasonal water flow (like Monsoon) diversion to storage and irrigation systems is vital for WEPC promotion.

6) Jungle fires, burning of Fossil Fuels and Explosive usage in warfare are huge and critical GHT, GHG, soot and pollution feeders.

7) Mankind's Obstructions of WEPC and PAWHP operations are extremely detrimental for safe life existence on this Globe.

\section{Recommendations}

It is recommended that:

1) WEPC must be immediately mobilized throughout the world by the Mankind.

2) All the opportunities of PAWHP must be safeguarded and immediately mobilized.

3) Immediate and Strict Control must be imposed on all the following 3 huge and critical GHT, GHG, soot and pollution feeders.

a) Fossil Fuels production and Use.

b) Explosive production and use in warfare.

c) Jungle fires.

4) Heavy International taxes must be charged on both production and usage of each item stated in above recommendation No.3 and used for Global Heating Control.

5) In view of extremely immense International concern, all political, social, territorial, cultural, civilizations and religious bindings and obstructions in mobilization activities needed for the above Serial $1-4$ should be overruled at all cost.

6) For financial gains through sale of ammunition and armaments, hence the huge amount of heat and pollution input to the Global environments should be curtailed and the International Community in general and advanced countries in particular should devise ways for reversal of this field to some others safe and productive fields favoring human welfare. For God sake, do 
not put the whole Globe on the top of huge explosive for your meager financial gains through human torture, but get it through human service and welfare.

7) The slow and persistent poisoning of petroleum and coal industries should also be controlled; particularly the power plants based on these fuels should be curtailed and shifted to heat and pollution free power generation i.e. shifted to hydro, wind, solar panels, oceans currents and tides resources etc. Such new plants must be discouraged severely, particularly where other resources could be used.

8) UNO should devise a separate and particular setup to manage.

a) Arrangement for finances collection from all the countries as per both their production and use of petroleum, coal, other fossil fuels and explosives.

b) Safety measures development to avoid jungle fires eruption and their immediate control and arrange its International Supervisory Forum.

c) Estimation of heat and pollution input to the environment by the jungle fires and compensate it from all those responsible of it.

d) Collection of Donations from financially well-off countries, persons and organizations and loans or investments from the banks from all over the world for the goal to achieve within few years and to compete with the Global temperature and heat contents rise. The loans collected by UNO for this purpose may be paid from the funds collected as charges of heat and pollution feed to the environment by all the countries.

9) A strategy should be devised to resolve the International and sectarian issues without indulging in explosive based warfare. International court should be mobilized to resolve the chronicle issues and International Forums be developed to solve International problems without veto power of any one and all should obey the decisions and non-cooperatives must be persuaded with strict International Embargos.

10)The flow of water to sea, particularly in Africa and Australia must be obstructed as far as possible. It should be diverted to irrigation or at least it should be regulated for persistent flow throughout the year for its maximum exposure to evaporation. On some tracks veers may be made to make the water available throughout the year for continuous evaporation and wildlife requirements. Any possible diversion of water to barren areas must be carried out on priority. Water evaporation at the land in place of its flow to the existing water bodies throughout the world must be promoted.

\section{Conflicts of Interest}

The authors declare no conflicts of interest regarding the publication of this paper.

\section{References}

[1] The 97\% Consensus on Global Warming. 
https://www.skepticalscience.com/global-warming-scientific-consensus-intermediat e.htm https://skepticalscience.com/graphics.php?g=242

[2] Watts, J. (2018) Global Warming Should Be Called Global Heating, Says Key Scientist. UK Met Office Professor Tells UN Summit Earth's “Energy Balance” Is Changing.

https://www.theguardian.com/environment/2018/dec/13/global-heating-more-accu rate-to-describe-risks-to-planet-says-key-scientist

[3] Nazeer, M.M. (1997) Pakistan Resources Proficiency in Global Fever, Greenhouse Gasses and Atmospheric Pollution Control and Need of Their Mobilization. NSMTCC 97 on Environmental Pollution, Islamabad, 24-26 February 1997, 125-137.

[4] Cheng, L., et al. (2017) Improved Estimates of Ocean Heat Content from 1960 to 2015. Science Advances, 3, e1601545. https://doi.org/10.1126/sciadv.1601545 http://advances.sciencemag.org/content/3/3/e1601545.full https://www.eurekalert.org/pub releases/2017-03/ioap-ans031317.php

[5] Dahlman, L. and Lindsey, R. (2018) Climate Change: Ocean Heat Content. https://www.climate.gov/news-features/understanding-climate/climate-change-ocea n-heat-content

[6] https://www.economist.com/democracy-in-america/2011/01/24/climate-change-an d-evolution

[7] https://www.eea.europa.eu/data-and-maps/figures/global-annual-average-temperat ure-deviations-1850-2007-relative-to-the-1850-1899-average-in-oc-the-lines-refer-t o-10-year-moving-average-the-bars-to-the-annual-land-and-ocean-global-average2/observed-global-annual-average-temperature

[8] Annual Mean Temperature Change for Land and for Ocean NASA GISTEMP 2017 October. From Wikimedia Commons, the Free Media Repository. https://commons.wikimedia.org/wiki/File:Annual Mean Temperature Change for Land and for Ocean NASA GISTEMP 2017 October.png

[9] http://www1.lsbu.ac.uk/water/water on earth.html\#cycle

[10] http://www.geocoops.com/uploads/2/4/5/3/24532387/1823846.jpg?804

[11] Nazeer, M.M. (2019) Tragic Aftermath of Californian Jungle Fire and Hawaiian Volcano Out-Burst, a Warning about Persistently Rising Global Warming, Resulting into High Rated Disaster's Chain. Open Access Library Journal, 6, e5118. https://doi.org/10.4236/oalib.1105118

[12] http://iedro.org/articles/water-vapor-and-global-warming

[13] Nazeer, M.M., et al. (1998) Role of Earth Shape and Rotation in Generating and Tracking of Cyclones. Journal of Natural Science and Mathematics, 38, 217-227. 